\title{
Production of Nanostructured Silver from Waste Radiographic Films Using a Microwave-Assisted Hydrothermal Method
}

\author{
Bruna S. Sá ${ }^{1}$ Cecilia A. Zito ${ }^{1}$ Tarcísio M. Perfecto ${ }^{1} \cdot$ Diogo P. Volanti $^{1}$ (D)
}

Published online: 30 July 2018

(C) The Minerals, Metals \& Materials Society 2018

\begin{abstract}
Radiographic films, widely used in medical and dental diagnosis, are an excellent source of silver (Ag), due to their content of light-sensitive Ag compounds. After their use, the films are commonly incorrectly thrown away in the regular trash, causing potential environmental damage. Thus, sustainable methods for recovering Ag from discarded radiographic films are desirable for economic reasons and environmental preservation. In this study, we performed the Ag recovery from waste radiographic films and carried out its structural, chemical, and morphological characterization. First, a solution of commercial bleach, based on sodium hypochlorite $(\mathrm{NaClO})$, was used to separate $\mathrm{Ag}$ from radiographic films. Then, a microwave-assisted hydrothermal method was applied to produce nanometric metallic Ag using sucrose as a green reductant and sodium hydroxide $(\mathrm{NaOH})$. The obtained product was composed of relatively high purity $(\sim 97 \%)$ nanostructured Ag (NS-Ag). Thus, the proposed procedure was efficient, and a promising approach for Ag recovery from radiographic films since the obtained NS-Ag might be used in a wide range of technological applications.
\end{abstract}

Keywords Silver recovery $\cdot$ Nanohydrometallurgy $\cdot$ Sustainability $\cdot$ Radiographic plate $\cdot$ Green reductant

\section{Introduction}

Silver (Ag) has been increasingly used from medieval coins to the current metal alloys. This metal composes several materials, such as mirrors, jewelry, and electronic equipment. Noteworthy, radiographic films are an excellent source of $\mathrm{Ag}$, since they contain around $2 \% \mathrm{Ag}$ by weight in metallic and halide forms [1] in addition to the gelatin based on animal protein [2] and a plate of polyethylene terephthalate (PET) [3]. Thus, the incorrect disposal of the radiographic films can lead to the contamination of the environment, because, besides the plastic, Ag can also

The contributing editor for this article was Hongmin Zhu.

Electronic supplementary material The online version of this article (https://doi.org/10.1007/s40831-018-0187-z) contains supplementary material, which is available to authorized users.

Diogo P. Volanti

diogo.volanti@unesp.br

1 Laboratory of Materials for Sustainability (LabMatSus), Ibilce, São Paulo State University (Unesp), R. Cristóvão Colombo 2265, S. J. Rio Preto, SP 15054-000, Brazil cause severe damages to nature, and even adverse impacts on living organisms [4]. For instance, argyria is a disease that makes the skin turn gray due to large deposits of $\mathrm{Ag}$ salts in parts of the human body [5]. Also, the accumulation of Ag can cause morphological aberrations in fish [6].

Nanostructured $\mathrm{Ag}^{\circ}$ (NS-Ag) has applications in several areas. In medicine, studies about the inhibition of HIV-1 virus by the action of $\mathrm{Ag}$ nanoparticles have been conducted for the development of prevention treatments [7]. Moreover, NS-Ag has been applied in the production of antibacterial objects [8], sensors [9], and conductive inks [10]. Thus, Ag recovery from discarded objects is a meaningful way to protect the environment concomitantly with the generation of resources for technology development.

Some methods for recovering $\mathrm{Ag}$ from waste radiographic films have been demonstrated previously $[1,2,11]$. However, the structural, chemical, and morphological characterizations of the recovered $\mathrm{Ag}$ have rarely been reported. In this study, we demonstrate a novel approach to produce nanosized $\mathrm{Ag}$ from waste radiographic films based on two steps. First, Ag was removed from the PET plates by a chemical process, and then NS-Ag products were 
produced by a microwave-assisted hydrothermal (MAH) method.

\section{Experimental}

The process of Ag recovery is an adaptation of a previously reported methodology [11]. First, the radiographic films were cut in rectangular pieces. Then, the pieces were immersed in a $\mathrm{NaClO}$ solution $\left(0.13-0.17 \mathrm{~mol} \mathrm{~L}^{-1}\right)$, which was prepared from a commercial bleach, until the dark material was separated from the PET plate. The mixture was decanted overnight, and the sediment was collected by centrifugation and dried. Subsequently, $2.3 \mathrm{~g}$ of the collected product, $4.6 \mathrm{~g}$ of sucrose $(99.8 \%)$, and $2.3 \mathrm{~g}$ of $\mathrm{NaOH}(97.0 \%)$ were added to $70 \mathrm{~mL}$ of deionized water, and the mixture was homogenized under magnetic stirring. Afterward, the obtained homogeneous mixture was transferred to a polytetrafluoroethylene autoclave, sealed, and heated at $140{ }^{\circ} \mathrm{C}$ for $1 \mathrm{~h}$ in a microwave oven $(2.45 \mathrm{GHz} /$ $800 \mathrm{~W})$ [12]. Finally, the product was centrifuged at $7000 \mathrm{rpm}$ for $10 \mathrm{~min}$, washed with deionized water, and dried at $75^{\circ} \mathrm{C}$.

The sample characterization was performed by X-ray diffraction (XRD, Rigaku MiniFlex 300) using $\mathrm{Cu} \mathrm{K} \alpha$ radiation with a step-size of $0.01^{\circ}$ at a rate of $2^{\circ} \mathrm{min}^{-1}$; Fourier-transformed infrared spectroscopy (FTIR, Perkin Elmer Spectrum Two spectrophotometer); thermogravimetric (TG) analysis (Perkin-Elmer TGA 4000) under a $\mathrm{N}_{2}$ flow $\left(20 \mathrm{~mL} \mathrm{~min}^{-1}\right)$ at a heating rate of $20{ }^{\circ} \mathrm{C} \min ^{-1}$; field-emission scanning electron microscopy (FESEM, JEOL JSM-7500F); energy dispersive X-ray spectroscopy (EDS, JEOL JSM-7500F); X-ray photoelectron spectroscopy (XPS, K-Alpha Thermo Scientific spectrometer). The calibration of the XPS spectra was carried out using the $\mathrm{C} 1 \mathrm{~s}$ peak at $284.8 \mathrm{eV}$.

\section{Results and Discussion}

The process of Ag recovery can be explained in a few steps. First, the immersion of the radiographic films in the $\mathrm{NaClO}$ solution promotes the separation of the dark gelatinous material from the PET plate. Then, the $\mathrm{NaClO}$ solution extracts $\mathrm{Ag}$ from the gelatinous material, since $\mathrm{NaClO}$ allows the hydrolysis of the proteins which compose the gelatin. This occurs because of the alkaline $\mathrm{pH}$ of the reactive medium [11] as a result of the $\mathrm{NaClO}$ hydrolysis according to the following reaction (Eq. 1) [13]:

$\mathrm{ClO}_{(\mathrm{aq})}^{-}+\mathrm{H}_{2} \mathrm{O}_{(\mathrm{l})} \rightleftharpoons \mathrm{HClO}_{(\mathrm{aq})}+\mathrm{OH}_{(\mathrm{aq})}^{-}$

Then, $\mathrm{ClO}^{-}$reacts with $\mathrm{Ag}$ to produce $\mathrm{AgCl}$ precipitate according to the XRD pattern shown in the supplementary data (Figure S1a). Afterward, the addition of sucrose and $\mathrm{NaOH}$ leads to the formation of $\mathrm{Ag}_{2} \mathrm{O}$ in the reaction medium (see Figure S2a). Figures $\mathrm{S} 1 \mathrm{~b}$ and $\mathrm{S} 2 \mathrm{~b}$ show the FTIR spectra of the samples produced after the use of the $\mathrm{NaClO}$ solution, and the addition of sucrose with $\mathrm{NaOH}$, respectively. In both cases, it was possible to observe peaks referring to $\mathrm{OH}$ (at 1110 and $1108 \mathrm{~cm}^{-1}$ ) and $\mathrm{C}=\mathrm{O}$ (at 1727 and $1729 \mathrm{~cm}^{-1}$ ) vibrations, besides other peaks referring to the presence of more organic groups adsorbed on the material surface [14].

Afterward, the temperature and alkaline conditions during the microwave-assisted process induce the total hydrolysis of the gelatin and the extraction of the remaining Ag. Moreover, due to the alkaline medium and high temperature, sucrose is hydrolyzed to glucose and fructose [15]. Both glucose and fructose are reducing sugars which can finally produce metallic $\mathrm{Ag}$ from $\mathrm{AgCl}$ and $\mathrm{Ag}_{2} \mathrm{O}$.

After the recovery procedure, the product characterization was performed to confirm the efficiency of the proposed method. XRD analysis was used to identify the crystalline structure of the sample. The XRD pattern (Fig. 1) of the NS-Ag corresponded to the face-centered cubic of the metallic Ag, according to the JCPDS data card 04-0783. No diffraction peaks corresponding to $\mathrm{Ag}_{2} \mathrm{O}$ or other compounds were observed, suggesting the formation of pure metallic Ag.

The FTIR was used to investigate the presence of residual organic compounds (Fig. 2) in the sample. Only a few organic impurities were observed. Two small peaks were verified in the regions at around 1715 and $1080 \mathrm{~cm}^{-1}$ referring to the $\mathrm{C}=\mathrm{O}$ and $\mathrm{OH}$ vibrations, respectively [14]. Such chemical bonds might be related to decomposition products of sucrose. According to the TG analysis (Figure S3), the product lost $3.02 \%$ in weight in the

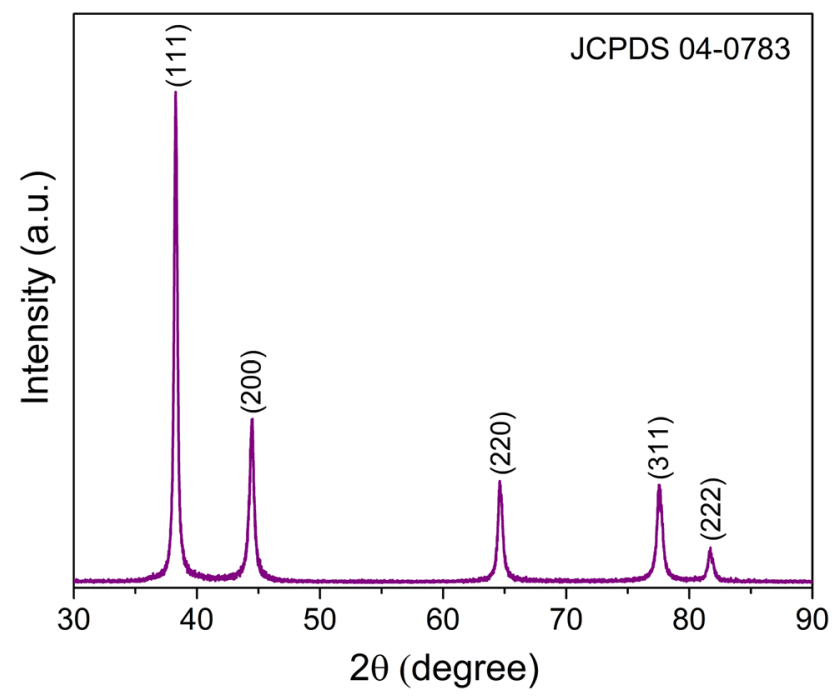

Fig. 1 XRD pattern of the produced NS-Ag (Color figure online) 


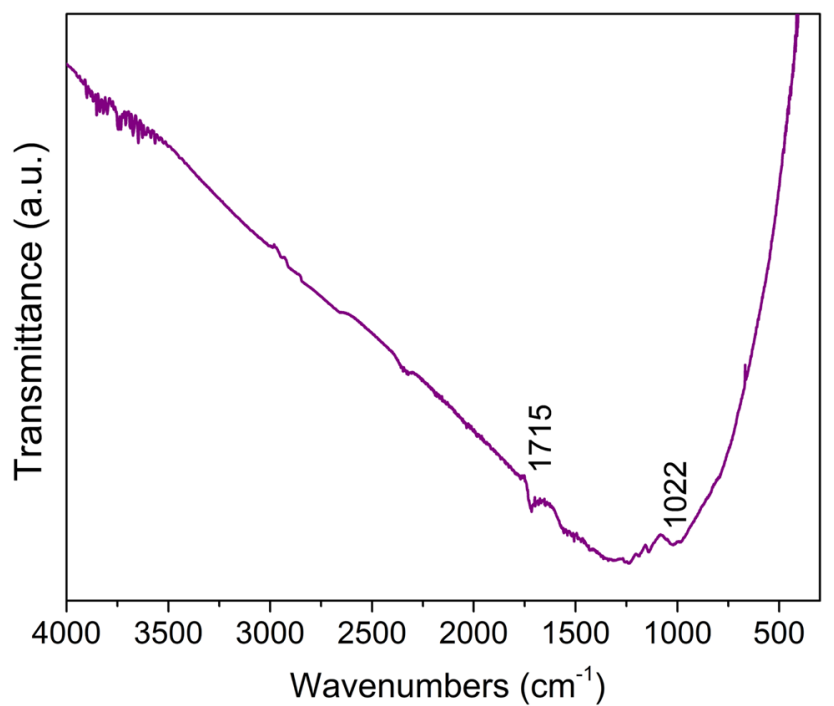

Fig. 2 FTIR spectrum of the produced NS-Ag (Color figure online)

temperature range of $220-485^{\circ} \mathrm{C}$ due to the thermal decomposition of residual organic compounds.

The surface elemental composition and the electronic structure of the sample were explored by XPS analysis. Figure 3a shows the survey scan XPS spectrum of the sample. Only peaks related to $\mathrm{Ag}, \mathrm{C}$ and $\mathrm{O}$ elements were observed. Furthermore, only low-intensity $\mathrm{Na}$ peaks have been found. Therefore, the sample presented a relatively high Ag purity.

The high-resolution XPS spectrum of $\mathrm{Ag} 3 \mathrm{~d}$, shown in Fig. 3b, reveals two peaks at 374.1 and $368.1 \mathrm{eV}$, corresponding to the $\mathrm{Ag} 3 \mathrm{~d}_{3 / 2}$ and $\mathrm{Ag} 3 \mathrm{~d}_{5 / 2}$, respectively. The positions of these two peaks and the energy difference between them $(6.0 \mathrm{eV})$ evidence the metallic state of the obtained Ag [16].

Figure $3 \mathrm{c}$ shows the $\mathrm{C} 1 \mathrm{~s}$ high-resolution XPS spectrum. The peak can be fitted with three components. The first at $284.8 \mathrm{eV}$ corresponds to $\mathrm{C}-\mathrm{C}$, the second one at $286.5 \mathrm{eV}$ is related to $\mathrm{C}-\mathrm{O}$, and the last at $288.4 \mathrm{eV}$ is assigned to $\mathrm{O}-$ $\mathrm{C}=\mathrm{O}$ [17]. These peaks can be related to the few organic residues derived from the use of sucrose in the Ag recovery process. The O 1s XPS spectrum (Fig. 3d) reveals two peaks associated to the bounds with carbon at $532.8 \mathrm{eV}$ $(\mathrm{O}=\mathrm{C})$ and $532.1 \mathrm{eV}(\mathrm{O}-\mathrm{C})$. No peak related to the formation of metal oxides (at 529-530 eV) was observed $[16,17]$, confirming the presence of only metallic Ag in the sample. Moreover, a small peak of $\mathrm{Na}(535.5 \mathrm{eV})$ was noticed owing to the use of the reagents $\mathrm{NaClO}$ and $\mathrm{NaOH}$ in the synthesis.

The EDS spectrum (Fig. 4a) shows the chemical composition of the sample. Only peaks related to $\mathrm{Ag}$ and $\mathrm{O}$ were observed, suggesting the purity of the obtained NSAg. As revealed in the FTIR an XPS analyses, the O
Fig. 3 a Survey XPS spectrum of obtained NS-Ag. Highresolution XPS spectra of $\mathbf{b} \mathrm{Ag}$ $3 \mathrm{~d}$, c C 1s, and d O 1s (Color figure online)
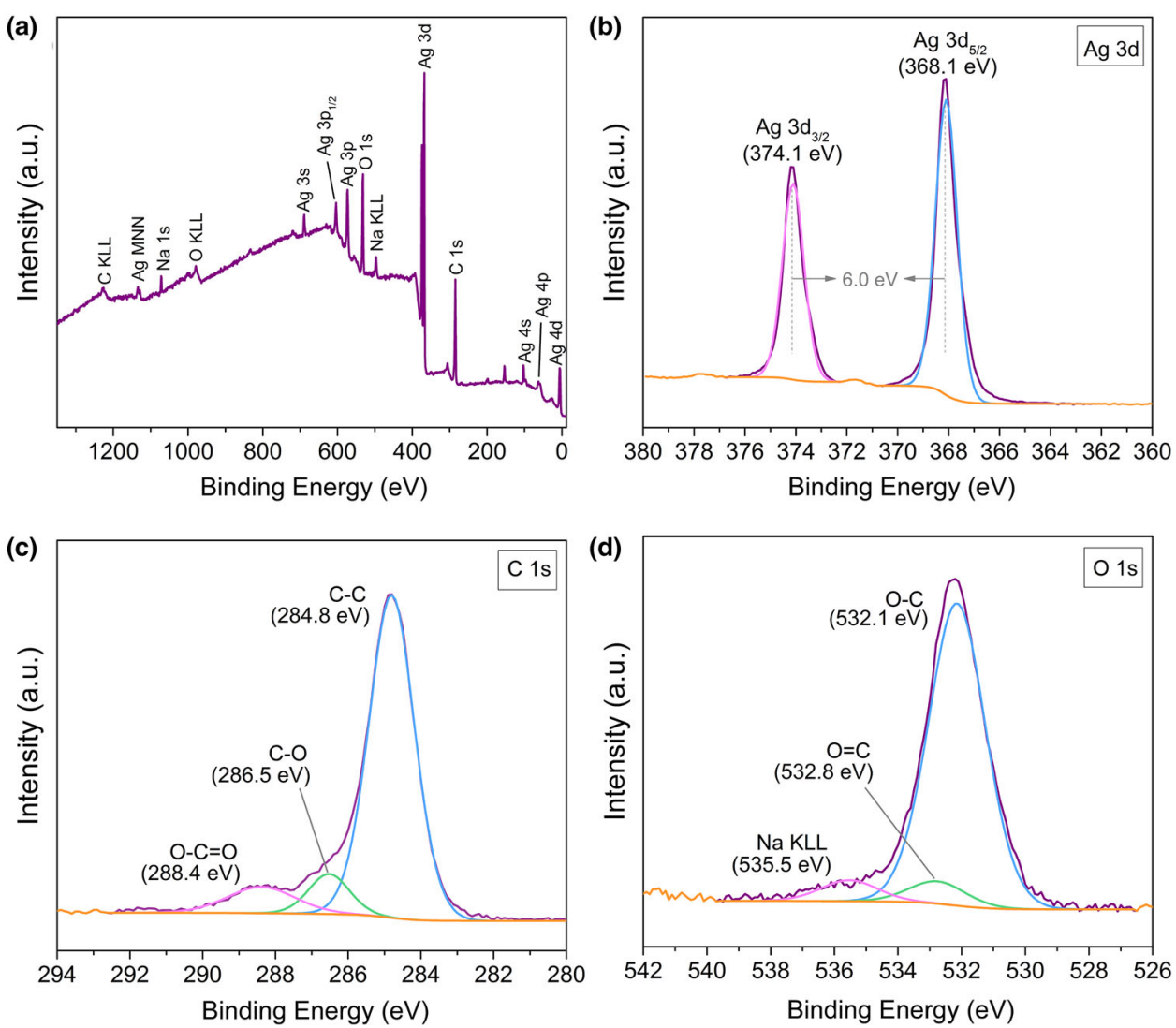
Fig. 4 a EDS spectrum and b-d FESEM images of the NS$\mathrm{Ag}$ at different magnifications (Color figure online)
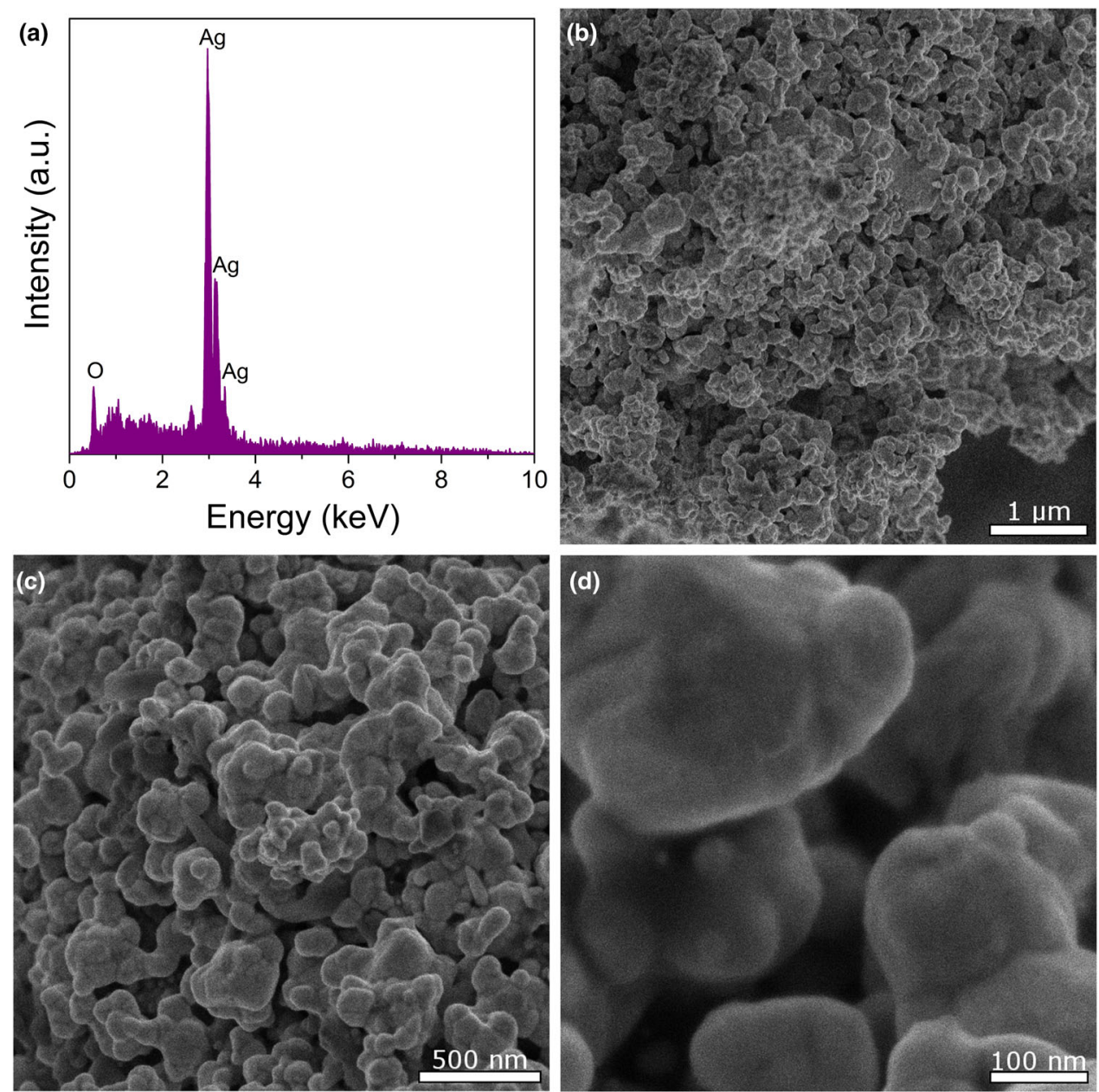

present in the sample is chemically bonded to $\mathrm{C}$ and $\mathrm{H}$, indicating that the $\mathrm{O}$ peak in the EDS spectrum is not related to the $\mathrm{Ag}_{2} \mathrm{O}$ formation. FESEM analysis was conducted to elucidate the morphology of the recovered Ag. The FESEM images of the sample (Fig. 4b-d) revealed an agglomerate of nanoparticles with a diameter of 40-250 nm.

\section{Conclusion}

In conclusion, NS-Ag products were produced from waste radiographic films. The proposed method using the MAH processing has proven to be efficient, mainly because of the formation of metallic $\mathrm{Ag}$ in the nanoscale size range with relatively high purity. Furthermore, the employed recycling method is promising due to the environmental benefit and the possibility of using the obtained NS-Ag for many technological applications.

Acknowledgements The authors gratefully acknowledge support through grants from the São Paulo Research Foundation - FAPESP (Grants 2017/01267-1 and 2017/13230-5), and CNPq/PIBIC/Unesp
(ID: 42591). The XPS and FESEM facilities were provided by the Brazilian Nanotechnology National Laboratory - LNNano/CNPEM (Proposal No. 21594) and LMA/IQ/Unesp, respectively.

\section{Compliance with Ethical Standards}

Conflict of interest The authors declare that they have no conflict of interest.

\section{References}

1. Aktas S, Morcali MH, Yucel O (2010) Silver recovery from waste radiographic films by cementation and reduction. Can Metall Q 49:147-153

2. Shankar S, More SV, Laxman RS (2010) Recovery of silver from waste X-ray film by alkaline protease from Conidiobolus Coronatus. Kathmandu Univ J Sci Eng Technol 6:60-69

3. Davies C, Naoush HF, Rees GJ (1996) Recovery of poly(ethylene terephthalate) (PET) from used X-ray film, Part 1. A review of current problems and a chemical method for recovery of silver and PET. Polym Int 41:215-225

4. Masebinu SO, Muzenda E (2014) Review of silver recovery techniques from radiographic effluent and X-ray film waste. Proc World Congr Eng Comput Sci II:22-24 
5. Lansdown ABG (2010) A pharmacological and toxicological profile of silver as an antimicrobial agent in medical devices. Adv Pharmacol Sci. 2010:Art ID 910686. https://doi.org/10.1155/ 2010/910686

6. Fabrega J, Luoma SN, Tyler CR et al (2011) Silver nanoparticles: behaviour and effects in the aquatic environment. Environ Int 37:517-531

7. Elechiguerra JL, Burt JL, Morones JR et al (2005) Interaction of silver nanoparticles with HIV-1. J Nanobiotechnol 3:1-10

8. Abou El-Nour KMM, Eftaiha A, Al-Warthan A, Ammar RAA (2010) Synthesis and applications of silver nanoparticles. Arab J Chem 3:135-140

9. Jia M, Wang T, Liang F, Hu J (2012) A novel process for the fabrication of a silver-nanoparticle-modified electrode and its application in nonenzymatic glucose sensing. Electroanalysis 24:1864-1868

10. Rajan K, Roppolo I, Chiappone A et al (2016) Silver nanoparticle ink technology: state of the art. Nanotechnol Sci Appl 9:1-13
11. Kuya MK (1993) Recuperaçao de prata de radiografias: uma experiência usando recursos caseiros. Quim Nova 16:474-476

12. Silva EL, Varela JA, Almeida DKA, Volanti DP (2010) Aided device for hydrothermal synthesis of nanostructured oxides, particularly obtaining particles of metal oxides, comprises container, in which hydrothermal reaction takes place, and lid for container. Patent No. BR200815393-A2

13. Voguel AI (1979) Textbook of macro and semimicro qualitative inorganic analisys, 5th edn. Longman, New York

14. Silverstein RM, Webster FX (2005) Spectrometric identification of organic compounds, 6th edn. Wiley, New Jersey

15. Whistler RL, BeMiller JN (1958) Alkaline degradation of polysaccharides. Adv Carbohydr Chem 13:289-329

16. Moulder JF, Stickle WF, Sobol PE, Bomben KD (1992) Handbook of X-ray photoelectron spectroscopy. Perkin-Elmer Corporation, Waltham

17. Thermo Scientific XPS Simplified (2018) https://xpssimplified. com/index.php. Accessed 3 Mar 2018 